\title{
Green HRM: Goal Attainment through Environmental Sustainability
}

\author{
Prof. Dr. Mohammad Main Uddin \\ Md. Rabiul Islam
}

\begin{abstract}
The green Human Resources Management has emerged from companies engaging in practices related to protection of environment and maintaining ecological balance. The slogan is earning profit through environmental sustainability. This paper proposes the development of a model of green human resource management by reviewing the literature on human resource aspects of environmental management. The study followed archival method of literature review. The literature has been classified on the basis of entry to exit processes in the HRM on the basis of available literature on green Human Resources. From the perspective of green human resource management, this study argues that Green HRM can play a useful role in business in promoting environment related issues by adopting and following the processes. Finally, the paper proposes some research agenda for the future study.
\end{abstract}

Key Words: HRM, sustainability, environment

\section{Introduction}

Concept of Green HRM: Green HRM is the use of human resource management policies to promote the sustainable use of resources within business organizations and more generally, promotes the cause of environmental sustainability (Mandip, 2012). The purpose of going green is to use products and methods that would not negatively impact the environment through pollution or depleting natural resources (Robinson, 2008). Thus, Green HRM involves environmentally-friendly human resource policies and practices that, on the one hand, will help organizations achieve its monetary goal through environmental branding and on the other hand protect environment from any negative impacts that might cause by the policies \& actions by the organizations.

Environmental Sustainability: Sustainability is often defined as the "ability to meet the needs of the present without compromising the ability of future generations to meet their needs (WCED, 1987 as cited in Cohen Toylor \& Muller, 2004). In the environmental literature, the concept of green management for sustainable development has various definitions; all of which generally, seek to explain the need for balance between industrial growth for wealth creation and safeguarding the natural environment so that the future generations may thrive (Daily \& Huang, 2001). Nevertheless, the issue of how an individual organization or entire society achieves sustainability from the green human resource management movement is still debatable and unclear. Thus, research on how business may structure their facilities to enhance for sustainability through green human resource management initiatives seems paramount. 


\section{Problems and Objectives}

To review extensive literatures in this field so as to identify gaps and scopes for further study.To develop a process model of green human resource management from entry to exit.

The purpose of going green is to use products and methods that would not negatively impact the environment through pollution or depleting natural resources (Robinson, 2008). If the use of natural resources is reduced by using alternative sources, it will have positive outcomes such as keeping the environmental footprint small, reducing waste and re-using materials as much as possible (Dallas, 2008). In addition, it will result in using scarce natural resources efficiently and effectively, while keeping the environment free from detrimental products.

Researchers in this area argued that environmental management system can only be effectively implemented if the companies have the right people with the right skills and competencies (Daily and Huang, 2001). Strategic HRM researchers argued that to achieve HR effectiveness, HR should be practiced as a whole and must be aligned with the business strategic goals, the primary means by which firms can influence and shape the skills, attitudes, and behavior of individuals to do their work and thus achieve organizational goals (Collins and Clark, 2003). Previously, businesses assumed that incorporating 'green' into their business strategy would cost money, but they now realize that ignoring negative impacts on the environment will be costly in the future (Van der Zee, 2008).

The topic of the green HRM is attracting increased attention among management scholars. Despite its importance to managers, employees, customers and other stakeholders, however, there are very few research studies that consider a complete process of HRM in organizations striving to achieve environmental sustainability. There is, thus, a growing need for the integration of environmental management into HRM.

\section{Data and Mathods}

With a view to accomplish the major objectives listed above, the present study adopted archival method of literature review so that it enables the researcher to structure the research, find gaps, scopes for further study and authentic knowledge base in this field (Tranfield et al., 2003; Renwick et al., 2008). Articles published on green HRM between 1996 and 2013 have been reviewed and a process model has been developed based on the review. The limitation of the study is that only the articles published and available online have been considered for the study.

\section{Discussion and Analysis}

The literatures have been classified from entry to exit process.

\subsection{Recruitment (entry)}

Induction for new recruits is seen to be needed to ensure they understand and approach their corporate environmental culture in a serious way (Wehrmeyer, 1996). Therefore sustainable development issues must be integrated into the recruitment process. In the 
U.K., environmental issues have an impact on recruitment, as survey data show that high achieving graduates judge the environmental performance and reputation of a company as a criterion for decision making when applying for jobs (Wehrmeyer, 1996 as cited in Renwick, et al., 2008). The latest CIPD/KPMG survey of 1000 respondents states that $47 \%$ of HR professionals feel that employees would prefer working for firms that have a strong green approach and 46\% stating that having one would help attract potential recruits(Phillips, 2007).

\subsection{Training and Development}

Employee training and development programs should include social and environmental issues at all levels, from technical health and safety considerations on the shop floor, to strategic sustainability issues at executive management and board level (Mandip, 2012). Green orientation programs for the newly higher employees should be an integral part of the training and development process. Examples of company environmental training in Britain include those at Carson Office Furniture Systems, Ready-Mixed Concrete, RollsRoyce, Albion Group, and Bristol-Myers Squibb, who include induction training for new staff, awareness training for more experienced employees, and training on specific green topics for staff specifically associated with environmental operations and co-ordination (Bird, 1996). At Adam Opel AG in Germany, environmental issues are integrated within the training programs given with all new projects and processes (North and Daig, 1996). Training by U.S. organizations in environmental management often involves regulatory requirements, employee awareness, and training on environmental quality management (Milliman and Clair, 1996, Weise, 1992).

Results from the Green teams program at KCC have seen only in 500 staff being trained effectively, green teams viewing other staff abdicating their responsibilities, some staff giving a token response or rejecting such environmental issues aggressively (perhaps because Green options were not well defined and difficult to quantify), and this initiative being difficult to maintain in the face of other managerial priorities. However, the Green teams at KCC have scored some successes, like establishing environmental management on departmental agendas, plans, and projects and seen KCC embrace a green agenda, i.e. towards culture chancge, and is achiving cost savings, helping departments gain access to corporate funds, and to implement programs in environmental management too (Beard and Rees, 2000)

\subsection{Performance Appraisal and Management}

Using performance management in environmental management presents the challenges of how to measure environmental performance standards across different units of the firm, and gaining useful data on the environmental performance of managers (Renwick, et al., 2008). Firms like Tata Group of Companies have installed corporate-wide environmental performance standards (which cover on-site use, waste management, environmental audits and the reduction of waste) to measure environmental performance standards and developing green information systems and audits (to gain useful data on managerial environmental performance) (Mandip, 2012). One way in which performance management systems can be successfully initiated in an organization is by tying the performance evaluations to the job descriptions mentioning the specific green goals and tasks. For example, performance appraisal can cover such topics as environmental incidents, usage 
of environmental responsibilities, reducing carbon emissions and the communication of environmental concerns and policy (Wehrmeyer, 1996 as cited in Renwick, et al., 2008).

\subsection{Employee Relations}

The use of employee participation in environmental management has been noted to help prevent pollution from workplaces (Wolters, Bouman and Peeters, 1995). Fernandez, Junquera and Ordiz (2003) conclude that environmental involvement approach in environmental management motivates the workers, allows them to detect problems like leakages in the production process and that delegating responsibilities to workers is based upon team knowledge of the causes of waste and how to reduce them-as seen in environmental involvement in waste reduction at Kodak, DuPont, and Proctor and Gamble In Britain, TUSDAC recommends that U.K. unions negotiate a sustainable workplaces framework agreement with employers to strengthen workplace employee engagement in sustainable development (TUSDAC, 2005). Employee grievance and discipline also has impact on the greenness of the firm. Brockett, 2006 states that environmentally unfriendly behavior may constitute a breach of contract and therefore possible grounds for dismissal.

Trade union plays a vital role in the establishing and implementing of environmental management goals of the firm. Trade unions in the U.K. are seen to offer a key role in terms of supporting environmental improvements through their traditional health and safety concerns in the workplace (Wehrmeyer, 1996 as cited in Renwick, et al., 2008)

\subsection{Pay and Reward}

Attainment of specific environmental initiatives should be integrated into the compensation system by offering employees a benefit package that rewards employees for green performance. Monetary -based environmental reward systems have been developed an important proportion of monthly managerial bonuses are dependent upon performance outcomes in environmental management (Milliman \& Clair, 1996). In the U.S., companies such as Du Pont base their executive compensation and bonus system for middle maagers and senior officers in part on environmental etewardship practices, where bonuses can be over 10 percent if they develop an environmentally benign pesticide for agriculture or a non-polluting product (May \& Flannery, 1995; Snyder, 1992). In Europe, companies like Neste Oy in Finland include environmental performance goals as a standard part of their bonus system and line managers have licence to allocate rewards to motivate employees at Neste Oy in Sweden (Ramus, 2001). In Britain, at ICI environmental targets would form part of senior managers' PRP assessment (Snape, Redman, and Bamber, 1994).

\subsection{Exit}

Exit means voluntarily or involuntarily leaving the organization. As the last task of the green HRM process, the HR manager will carry out exit interview to those who are leaving. The results of the exit interview, if the exit is environmental related, need to be improved. Moreover, arrangement of outplacement counseling shall be made to those who are fired for their bad environmental performance. The goal of outplacement counseling, in this context, is to provide the leaving employees the knowledge base particularly about the environment so that they might be able to find a job elsewhere. In terms of staff exits, where 
dismissal occurs, it may be that any 'general debriefing should include an environmental dimension, and if staff resign, then HR managers need to discover why' (Wehrmeyer, 1996 as cited in Renwick, et al., 2008).

\subsection{A Process Model of Green HRM}

Green HRM is the set of activities (recruitment, training and development, performance and appraisal, employee relations, pay and reward) that direct at an organization's human resources with the aim of achieving organizational goals through ensuring environmental sustainability. The process begins with recruiting prospective green employees into the organization followed by green training and development, green performance management and appraisal, environment-friendly employee-employer relationships that focus on employee involvement, green performance based pay and rewards and ends with conducting exit interviews those who leaving the organization voluntarily or involuntarily and using the survey results to improve the employee management systems (shown in Figure-1). The major goal of green human resource management is to achieve the organizational financial goals through environmental sustainability (policies and actions focused on minimal or no environmental damage).

Figure 1: A process model of green hrm

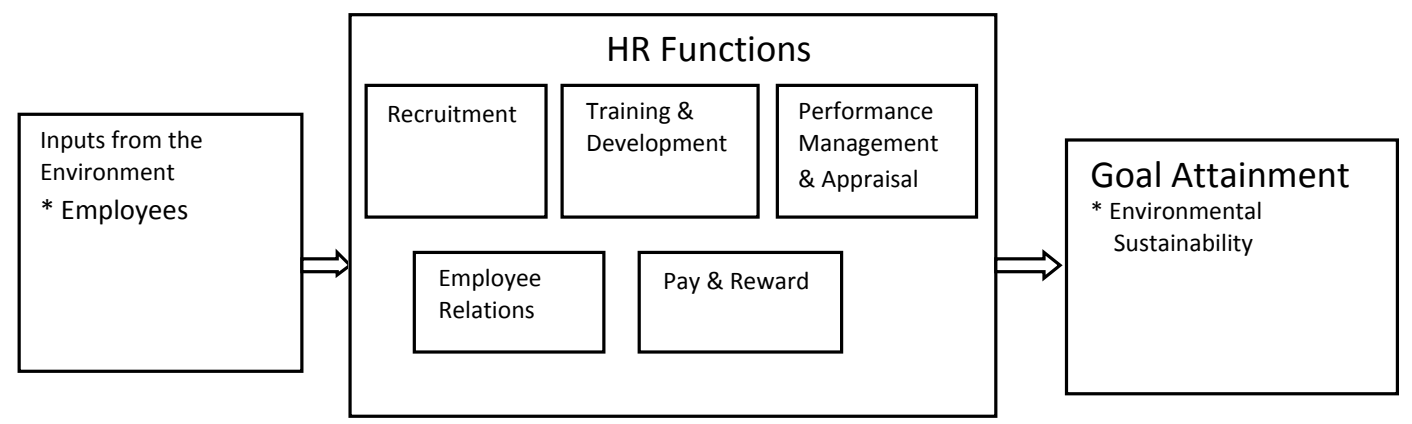

\section{Conclusions and Recommendations}

The green Human Resources Management has emerged from companies engaging in practices related to protection of environment and maintaining ecological balance. Green HRM encompasses all activities aimed at helping an organization carry out its agenda for environment management to reduce its carbon footprint in areas concerns on boarding and acquisition of human resources, their induction, performance appraisal \& management, training and development and pay and reward management. Green HRM can play a useful role in business in promoting environment related issues by adopting and following Green HR policies and actions. Green HRM can enhance corporate image and brand. Green HR will play an important role in making the employees aware of and concerned for preservation of natural resources and contribute in pollution control, waste management and manufacture of eco-friendly products. The proposed process model will help the practicing managers and future researchers follow green HRM techniques. The present study also proposes future researchers to fill the gap in the existing literatures by conducting empirical studies such as Green HRM practices in the manufacturing or service organizations (particularly the organizations that are polluting environment, Comparing Green HRM practices between developed and developing countries, Green perceptions, 
attitudes of employer and employees, barriers in the green HRM implementation etc.

\section{BIBLIOGRAPHY}

Beard, C., \& Rees, S. (2000). Green teams and the management of environmental change in a uk county council. Environmental Management and Health, 11(1), 27-38.

Bird, A., (1996). Training for environmental improvement in Wehrmeyer, W. (1996), 227246.

Brockett, J. (2006). Change agents people management. 23rd November, pp.1-19.

Cohen, E., Taylor, S., \& Muller, M. (2004). Hrm's role in corporate social and environmental sustainability. SHRM Foundation's Effective Practice Guidelines Series, 3.

Collins, C. J., \& Clark, K. D. (2003). Strategic human resource practices, top management team social networks, and firm performance: The role of human resource in creating organizational competitive advantage. Academy of Management Journal, 46(6), 740-51.

Daily, B. F., \& Huang, S. (2001). Achieving sustainability through attention to human resource factors in environmental management. International Journal of Operations and Production Management, 21(12),1539-1552.

Dallas, N. (2008). Green business basics: 24 lessons for meeting the challenges of global warming. New York: McGrow-Hill.

Fernandez, E., Junquera, B., \& Ordiz, M. (2003). Organizational culture and human resources in environmental issues. The International Journal of Human Resource Management, 14(4), 634-656.

May, D. R., \& Flannery, B. L. (1995). Cutting waste with employee involvement teams. Business Horizons, 28-38.

Mandip, G. (2012). Green hrm: People management commitment to environmental sustainability. Research Journal of Recent Sciences, 1, 244-252.

Milliman, J., \& Clair, J. (1996). Best environmental hrm practices in the US. In Wehrmeyer, W. (1996), 49-73.

North, K., \& Daig (1996). Environmental training in uk and german companies. In Wehrmeyer, W. (1996), 247-269.

Phillips, L. (2007). Go green to gain the edge over rivals. People Management, 9.

Renwick, D., Redman, T., \& Maquire, S. (2008). Green hrm: a review, process model and research agenda. Discussion Paper Series, University of Sheffield Management School, The University of Sheffield, 1-45.

Robinson, F. (2008). Going green: what does it really mean? [online] Available at: http:// ezinearticles.com/?Going-green!-What-does-it-really-mean?\&kd=2267926. 
Accessed: 15 March, 2014.

Smith, E. E., \& Perks, S. (2010). A perceptual study of the impact of green practice implementation on the business functions. Southern African Business Review, 14(3), 1-29.

Snyder, J. D. (1992). more execs find pay linked to ehs goals. Environment Today, (October),22.

Snape, E., Redman, T., \& Bamber, G. (1994). Remuneration and the manager, in managing managers: strategies and techniques for human resource management. Oxford: Blackwell.

Tranfield, D., Denyer, D., \& Smart, P. (2003). Towards a methodology for developing evidence-informed management knowledge by means of systematic review. British Journal of Management, 14(3) 207-222.

TUSDAC. (2005). Greening the workplace. From: www.Defra.gov.uk/environment/ tusdac/ Accessed: 15 March, 2014.

Weise, B. (1992). Integrating total quality principles into an environmental training program. Total Quality Environmental Management, 245-51.

Wolters, T., Bouman, M., \& Peeters, M. (1995). Environmental management and employmet: pollution prevention requires significant employee participation. Greener Management International, 11, 63-72. 